\title{
A study of case-holding in leprosy patients in Asia, based on duration of treatment, 1976-80
}

\author{
P J COLLIER \\ The Leprosy Mission (International), 50 Portland Place, London \\ $W 1 N 3 D G$
}

Received for publication 29 November 1982

\begin{abstract}
Summary From 14 different centres treating leprosy patients in Asia, a study was made of the periods of time for which patients attended during the years 1976-80. They were divided broadly into 'local' and 'non-local', the former being essentially from allocated, nearby leprosy control areas (but also to a lesser extent from the vicinity of the base or hospital, if this was not in fact in the control area). The latter were from 'all other areas' and included visitors (rich and poor), vagrants and patients with no fixed address. Within the first year after starting treatment, $32.4 \%$ of 'local' and $62.9 \%$ of 'non-local patients were lost, and 2 years later they had not returned and no information had been received of their removal from the area, or death. Data are further presented on the percentage rate of loss for 5 years, and at the end of this period $66 \%$ of local and $88 \%$ of non-local patients had been lost. The possibility is discussed that in the case of 'non-local' patients these figures may be less disconcerting than they appear, since many may have reported back to some other leprosy control unit in their area of origin, or to another part of the country. The figures for loss of 'local' patients are, however, considered to be serious and possible reasons are discussed. The collection of these figures on case-holding and their presentation to the staff concerned had an almost immediately beneficial effect in raising standards of work. Possibly the most important factor in achieving this was an even greater attention to personal contact with each patient.
\end{abstract}

\section{Introduction}

It takes a long time to treat leprosy. Although the recent WHO recommendations on multiple drugs ${ }^{1}$ considerably shorten the treatment periods for all types of leprosy, case-holding for adequate periods of time is still extremely important.

To find out whether we treat patients long enough to do any good, The Leprosy Mission (International) set up a study in 1976 to assess case-holding in 14 centres in Asia. The regrettably impersonal phrase 'case-holding' is used with reluctance for what is one of the most essentially personal aspects of leprosy work, including not only the duration of attendance, but also regularity and the 
quality of care given to patients by the staff. This study does not attempt to analyse regularity of attendance within any given period or to assess the quality of work; rather it concentrates on the periods of treatment (in months and years) for which patients attended after first registration.

\section{Patients and methods}

The centres chosen were regarded as having average or above average standards of work and good record keeping. All patients were treated with dapsone monotherapy. Details of patients and their attendances were recorded and analysed by computer, the present study being made on data collected up to October 1980. Since both commencement and attendance dates were recorded, analysis could be made on the basis of the length of time for which treatment was taken in the case of those patients who had discontinued it. Patients were classified as 'local' and 'non-local'. 'Local' patients were in nearby, allocated project areas but also included a few in the vicinity of the hospital or base clinic, in instances in which this was not actually in the project area. 'Non-local' patients were from 'all other areas' and included visitors both rich and poor, vagrants and those with no fixed address.

Of the data collected, only that which is complete and unaffected by distorting factors is used in the study. The count was of out-patients, including those who, during the study, became classified as 'Disease Arrested' or 'Lost by Non-attendance', but not those so classified before the study began. Patients known to have died, moved away or transferred to other centres were excluded. The scheme was set up in 1976, but as different centres commenced on different dates, 1977 was the first year when data collection was complete and consistent throughout. In 1979 there was a change in record-keeping practice, outside the control of the study. Most record-keepers in that year began to register new patients provisionally, only making the registration final after several attendances. Provisionally registered patients did not appear in the scheme. This would have distorted any figure for early losses based on that year. The years 1977 and 1978, however, contain undistorted data of new registrations and enough time has elapsed to study how patients who began treatment in those years have been held in their first year (and second, for those commencing in 1977). Data are held for patients who commenced treatment before 1976 provided they took treatment at some time after their centre entered the scheme. Complete figures for treatments commenced in the years before 1976 are not available. It is possible, however, to make valid comparisons between patient losses in the second, third, fourth and fif th years and figures of patients held up to the beginning of those years. In regard to Table 5, it should be noted that in making an attempt to ascertain if more or less frequent attendances made any difference to case-holding, the only readily available data were the number of weeks treatment (in tablets) given at each 
patient's last visit. In the case of patients lost, this meant the visit after which they did not return. The term 'standard' refers to the normal period of treatment given to most out-patients in the centres studied, and this was 4 weeks. Other patients had longer or shorter periods of treatment for some special reason. Shorter periods might be given to those with a clinical problem or considered to be 'at risk', whilst longer periods would be given to those considered to be safe and reliable.

\section{Results}

Data on case-holding in the first year, losses after the first year, the 5-year loss rate, variations in case-holding by type of leprosy, frequency of treatment and variations between centres are shown in the accompanying Tables 1-5. Data was also collected on the age and sex distribution in relation to case-holding and absolutely no significant correlation was noted in this study.

\section{Discussion}

It is not part of this report to compare centres. It is sufficient to state that there were wide fluctuations between them. At the centre with the best results, the

Table 1. Case-holding in the first year. Of 15,980 patients registered in 1977 and 1978 the following were lost within a year from their treatment commencement date

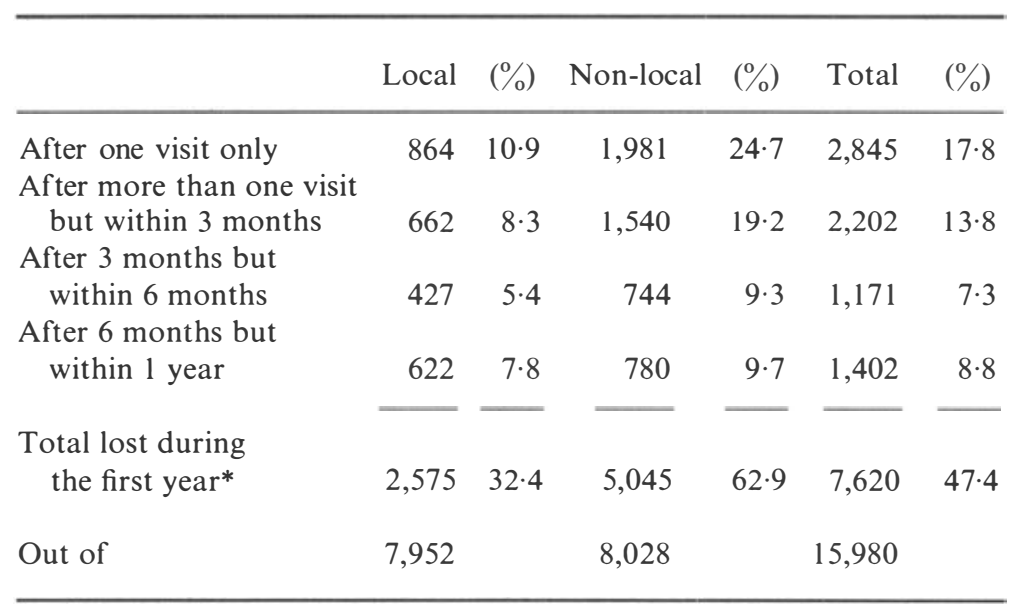

* The patients lost had not returned by October 1980, nor had information been received of their removal or death. 
Table 2. Losses after the first year. The figures from which rates of loss can be assessed

Second year

Total studied (i.e. patients who had already been held for 1 year, based on commencements in 1975 or 1977)

\begin{tabular}{rrr}
5,142 & 2,918 \\
676 & & 776 \\
\cline { 1 - 1 } $13 \cdot 1$ & & $26 \cdot 6$
\end{tabular}

Percentage loss in second year

If it is assumed that the first year loss rates had been the same as those calculated above, namely 'local' $32 \cdot 4$, 'non-local' $62 \cdot 8$, the second year losses can be expressed as a percentage of the original number

This adjusted percentage is: 'local' 8.9 , 'non-local' 9.9 and is referred to below as the 'accumulating loss'

Third year

Total studied (i.e. patients who had already been held for 2 years, based on commencements in 1974 or 1975)

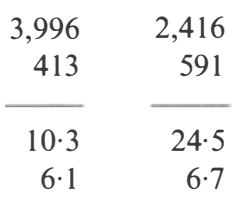

Percentage loss in third year

Accumulating loss

Fourth year

Total studied (i.e. patients who had already been held for 3 years, based on commencement in 1973, 1974 and 1975)

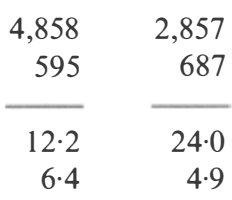

Percentage loss in fourth year

Accumulating loss

Fif th year

Total studied (i.e. patients who had already been held for 4 years, based on commencement in 1972, 1973 and 1974)

\begin{tabular}{|c|c|}
\hline 3,967 & 2,860 \\
\hline 526 & 642 \\
\hline $13 \cdot 3$ & $22 \cdot 4$ \\
\hline $6 \cdot 2$ & 3 \\
\hline
\end{tabular}

Percentage loss in fifth year

Accumulating loss

percentages held for 5 years were: 'local' $62 \%$, 'non-local' $26 \%$. The worst results were 'local' $12 \%$, 'non-local' $1 \%$. In the latter category of patient, although the figures (for instance in Tables 1 and 3) are extremely disconcerting, it is considered that many may have returned to their region of origin, or to some other part of the country, and reregistered there. However, information on this is lacking. In the case of 'local' patients, although case-holding was better, the 
Table 3. Combined table showing 5-year loss rate. This records the percentage rate of loss for 5 years, bearing in mind that the rates for each year are calculated on different groups of patients

\begin{tabular}{|c|c|c|c|c|c|c|}
\hline & \multicolumn{6}{|c|}{5 -year table $(\%)$} \\
\hline & \multicolumn{3}{|c|}{ Local } & \multicolumn{3}{|c|}{ Non-local } \\
\hline & Lost & Cumulative & Held & Lost & Cumulative & Held \\
\hline First attendance & $10 \cdot 9$ & $10 \cdot 9$ & $89 \cdot 1$ & $24 \cdot 7$ & $24 \cdot 7$ & $75 \cdot 3$ \\
\hline 3 months & $8 \cdot 3$ & $19 \cdot 2$ & $80 \cdot 8$ & $19 \cdot 2$ & $43 \cdot 9$ & $56 \cdot 1$ \\
\hline 6 months & $5 \cdot 4$ & $24 \cdot 6$ & $75 \cdot 4$ & $9 \cdot 3$ & $53 \cdot 2$ & $46 \cdot 8$ \\
\hline 1 year & $7 \cdot 8$ & $32 \cdot 4$ & $67 \cdot 6$ & $9 \cdot 7$ & $62 \cdot 9$ & $37 \cdot 1$ \\
\hline 2 years & $8 \cdot 9$ & $41 \cdot 3$ & $58 \cdot 7$ & $9 \cdot 9$ & $72 \cdot 8$ & $27 \cdot 2$ \\
\hline 3 years & $6 \cdot 1$ & $47 \cdot 4$ & $52 \cdot 6$ & $6 \cdot 7$ & $79 \cdot 5$ & $20 \cdot 5$ \\
\hline 4 years & $6 \cdot 4$ & $53 \cdot 8$ & $46 \cdot 2$ & $4 \cdot 9$ & $84 \cdot 4$ & $15 \cdot 6$ \\
\hline 5 years & $6 \cdot 1$ & $59 \cdot 9$ & $40 \cdot 1$ & $3 \cdot 5$ & $87 \cdot 9$ & $12 \cdot 1$ \\
\hline
\end{tabular}

Table 4. Variations in case-holding by type of leprosy*

\begin{tabular}{|c|c|c|c|c|}
\hline Recorded classification (Madrid) & $\mathrm{L}$ & B & $\mathrm{T}$ & I \\
\hline $\begin{array}{l}\text { Patients in the study who were lost } \\
\text { in the first year. Number }(\%) \\
\text { Patients lost in the following }\end{array}$ & $2,463(17)$ & $2,123(19)$ & $4,551(18)$ & $686(18)$ \\
\hline 3 years & $1,672(12)$ & $1,353(12)$ & $3,097(12)$ & $587(16)$ \\
\hline \multirow[t]{2}{*}{ Patients held over 4 years } & $10,254(71)$ & $7,581(69)$ & $17,712(70)$ & $2,464(66)$ \\
\hline & 14,389 & 11,057 & 25,360 & 3,737 \\
\hline
\end{tabular}

* This analysis is of patients in the study from all commencement years, including those where only partial data are available. It is valid for studying comparative case-holding but gives no indication of actual case-holding as do Tables 1 and 2.

Table 5. Frequency of treatment

\begin{tabular}{|c|c|c|c|}
\hline Losses (number \%) & Standard & Shorter & Longer \\
\hline First year & $4,752(21)$ & $749(17)$ & $4,316(16)$ \\
\hline Second to fourth years & $2,434(11)$ & $551(12)$ & $3,715(14)$ \\
\hline \multirow[t]{2}{*}{ Held over four years } & $15,134(68)$ & $3,179(71)$ & $19,074(70)$ \\
\hline & 22,320 & 4,479 & 27,105 \\
\hline
\end{tabular}


analysis nevertheless revealed how poor case-holding may be, even in centres with devoted staff and many years of experience in the out-patient treatment of leprosy. The reasons for this failure were far from clear but it was apparent that they were numerous and complex. A sociological study would be needed to clarify the situation and this could probably be best carried out with the whole-hearted cooperation and enthusiasm of local (indigenous) staff behind it. On the whole, the centres with better results were better all round, that is to say, good first-year results usually went with good later-year results: good 'local' results with good 'non-local' results. The best results were also found at centres where, in the writer's subjective judgement, there was most enthusiasm among staff, especially junior staff. Although far from clear cut, there is a suggestion in Table 5 that case-holding is slightly better for special cases receiving shorter or longer treatment periods.

A subsequent visit to a centre whose holding was poor proved extremely encouraging; the problem, once revealed, had been taken very seriously, with a resultant improvement in the standard of work. It was noted that the previous training and organization of health workers had placed great emphasis on case-finding as a primary objective; even the routine reports and returns tended to favour information on case-finding, with little attention to case-holding. In fact, case-finding must be combined with meticulous attention to case-holding in order to ensure the regular administration of drugs such as those recently recommended by WHO, ${ }^{1}$ for adequate periods of time. Case-holding should be taught as one of the first priorities in leprosy work generally and it should surely be recognized that any evaluation of a centre which does not take account of case-holding is misleading. Individual attention to patients and enthusiasm in the staff are vital factors if patients are to be cured before they are lost.

\section{Acknowledgements}

Gratitude is expressed to the 14 centres and their staff for cooperating in this study, and to the Leprosy Mission (International) for financing it.

\section{Reference}

1 WHO Study Group. Chemotherapy of Leprosy for Control Programmes. Technical Report Series No. 675. WHO: Geneva, 1982. 